\title{
A Comparative Study on Cost-Sharing in Higher Education-Using the Case Study Approach to Contribute to Evidence-Based Policy
}

\author{
Dominic Orr
}

\section{Introduction}

As Solesbury has stated, evidence-based policy is not so much the triumph of the social science - i.e. supply-driven - but expression of a greater pragmatism on the part of the policy development process - i.e. it is demand driven (Solesbury 2001). Evidence-based policy presents an opportunity, but also a direct challenge for researchers; that of providing evidence which is deemed relevant to and can be communicated and discussed within the policy-making process. This paper will present a project, which was commissioned by the European Union to provide advice to countries on changes to the balance of cost-sharing in higher education and their possible impacts (Orr et al. 2014a, b). This commission can be seen within the context of a multinational organisation encouraging the use of evidence-based policy for European and national decision-making in the policy sphere. In the case of the European Union, it set this as one of its strategic goals in 2002 (EU 2002). Indeed national governments appear to be increasingly persuaded by the argument that policies can be developed and evaluated based on the experiences of other countries, which have adopted similar policies. This is evidenced by frequent requests from national governments for such advice from multinational organisations, particularly the European Union and the Organisation for Economic Cooperation and Development (OECD). ${ }^{1}$ This means that enterprises, such as the

\footnotetext{
${ }^{1}$ For instance, the Thematic Review of Tertiary Education carried out by the OECD—http://www. oecd.org/edu/skills-beyond-school/thematicreviewoftertiaryeducation.htm.
}

D. Orr $(\bowtie)$

Deutsches Zentrum für Hochschul- und Wissenschaftsforschung (DZHW),

Hannover, Germany

e-mail: orr@dzhw.eu

(C) The Author(s) 2015

A. Curaj et al. (eds.), The European Higher Education Area,

DOI 10.1007/978-3-319-20877-0_51 
study presented here, are expected to facilitate policy learning between countries; these studies endeavour to make a virtue out of the fact that similar policies are implemented in different ways in different contexts, providing a rich ground for learning about how they work. The very virtue of being able to observe "living social experiments" also presents a huge challenge for research. This is of making the object of investigation comparable - of creating "relationally equivalent phenomena" (Phillips 2006) - to enable a comparative analysis. Additionally, policy and practice will ultimately never be the same in each country or over time, since it is shaped by the policy environment and the cultural-historic setting. This means that such a study has the second challenge of retaining the information within the analysis that is provided by the variety of contexts and the methods of implementation.

The specific task set for the researchers of the study presented here was formulated as follows: “...to provide a consolidated, accessible and up-to-date overview of the effects of different models of cost-sharing in higher education on participation patterns, the diversity, quality and relevance of educational provision and system efficiency."

With regard to the specific task of this study then, the third problem of such work is the comprehensiveness of the scope set by the commissioning agency. In this case the object of the study is cost-sharing (i.e. differing the contribution to funding higher education made by the state and private organisations, households or individual persons) and an evaluation of its impacts on higher education institutions' diversity, quality and relevance of educational provision, and on students' participation patterns.

The authors of the study chose the Realist Evaluation approach (Pawson and Tilley 1997, 2004; Pawson 2006) in order to satisfy these challenges and produce a policy-relevant analysis. This approach is designed to improve the understanding of how and why interventions work or do not work in a particular context and has been used frequently in the field of the evaluation of social programmes. As described in a recent paper by the Australian government (Westhorp 2014): "Rather than comparing changes for participants who have undertaken a programme with a group of people who have not, as is done in random control or quasi-experimental designs, a realist evaluation compares whether a programme works differently in different localities (and if so, how and why) or for different population groups (for example, men and women, or groups with differing socio-economic status). Realist evaluations can be undertaken with small or large groups and with qualitative and/or quantitative data."

The realist evaluation starts out from the programme theory, i.e. the theory about how to bring about a particular change which underpins the specific intervention. This is a common approach in political analysis, since all policy must have an explicit intension at the outset. Following the realist philosophy (Sayer 1992), the approach assumes that social systems are open systems and their boundaries are permeable and flexible. This has important ramifications for any analysis, because it means that the way a particular intervention works (i.e. its outcomes) will vary depending on the context in which it is set. The approach looks to outcomes, but 
particularly tries to identify "mechanisms" which enable these effects, as it also posits that these mechanisms sometimes fire and sometimes do not (i.e. outcomes may vary). Ultimately, it is people who determine whether this happens based on their decision-making, i.e. it is the interaction between the resources a programme provides, withholds, makes attractive or unattractive and the reaction of intended target group for the intervention which affects the outcome. Importantly, the assumption is that the mechanism will seldom be visible, but must be induced from this interaction. This is an important insight, which is helpful for policy reform, especially as many reforms have historically been found to be ineffective. In this regard, Andrews speaks of successful reforms as positive deviations and sees their openness to interactions and iterative adaptation as one common characteristic for success (Andrews 2013). Following this approach, the task of the researchers is to find or postulate programme theories, which can be investigated in the study.

In the following, the object of study (cost-sharing) will be briefly presented, and then the programme theories associated with it, the research questions and way of collating information for the study follow on from this. Subsequently, the results of the study will be discussed and the paper will close with general considerations for evidence-based policy.

\section{Cost-Sharing as Policy Issue}

Higher education systems have been and are continuing to be faced with the task of accommodating growing numbers of students without compromising the quality of education, and without creating undesired inequalities of access. The Council of the European Union stated in its strategy document for 2020 that "high quality will only be achieved through the efficient and sustainable use of resources - both public and private, as appropriate", whilst stressing that educational opportunity should be open to all citizens "irrespective of their personal, social or economic circumstances" (EU 2009). In 2011, a strategy document, specifically focussed on higher education within the framework of the overall EU strategy for supporting growth and jobs, laid out an agenda for the modernisation of Europe's higher education system (EU 2011). It too called for improvements in the quantity and quality of higher education graduates. Some of this growth should come from attracting "a broader cross-section of society into higher education" (EU 2011). The document stated that the total investment in higher education in Europe was too low, at $1.3 \%$ of GDP on average, behind both US and Japan, and that additional funding sources — "be they public or private"-were necessary (EU 2011). Internationally comparative data sets show that over the last two decades, there has been a shift towards larger shares of private funding of higher education. This tendency can be related to similar trends of privatisation in various areas of public services and administration (Megginson and Netter 2001). Even though higher education is not easily 
comparable to other types of public institutions, motives to aim for increased shares of private financial contributions in higher education are not unlike what drives privatisation of other social subsystems. They include: restricting public spending in times of severe fiscal constraints; reducing organisational inertia; and increasing efficiency by replacing monopolies through competitive environments, among other things.

The three main issues highlighted in the study as relevant to policy development in cost-sharing are impacts on sustainability, effectiveness and equity.

- Sustainability: In the context of very large and in many cases still growing higher education sectors, there is a need to find a funding model that can cope with this challenge. Whilst higher education is seen as a major driver of a nations' economic and social well-being, growth in higher education participation puts enormous strains on the public purse. This has led to higher education institutions (HEIs) diversifying their income sources, often by charging (higher) tuition fees. ${ }^{2}$ The advantage of tuition fees over other sources of supplementary income is that they do not tend to add additional costs to the institution or divert academic staff away from their core teaching responsibilities, as might be the case with entrepreneurial activities or research grants. Tuition fees can also represent a significant and reliable share of HEIs' income, unlike other possible sources of private funding (i.e. businesses and private donations).

- Effectiveness: This is about high-quality provision of higher education, which ensures that HEIs can provide students with the best possible training. There is an argument that the introduction of market mechanisms into the higher education system will increase HEIs' responsiveness to the needs of students and the labour market into which they should transition following graduation.

- Equity: There are in fact two perspectives to the equity issue. On the one hand, the equity notion argues that those who benefit directly from higher education should also contribute to its costs. If they do not, students' training is funded by all tax-payers, whether they themselves had a fair chance to study or not. On the other hand, the equity notion focuses on current barriers to higher education participation and places attention on the question of whether additional costs at entry to higher education will increase these barriers, making higher education participation even more unfair than before fees. These two perspectives do not have to be contradictions, since the additional money raised through private revenues can be used to particularly support under-represented groups.

As can be seen from these three issues, changes to cost-sharing are expected to affect the behaviour of institutions of higher education and of students. For this reason, the study adopts a twofold perspective on cost-sharing: firstly, cost-sharing

\footnotetext{
${ }^{2}$ This paper uses the term 'tuition fee' to refer to "any sum of money paid by students with which they formally and compulsorily contribute to the costs of their higher education" (Eurydice 2012).
} 
is investigated in terms of the changing balance of public and private revenues for institutions. From the perspective of HEIs, cost-sharing involves changes to the share of public and private funding as income sources (and the respective role of tuition fees, contract income, philanthropic donations, etc. as opposed to state funding). Secondly, the study also adopts the student perspective by investigating the costs students (and/or their families) cover in order to pursue higher education, but also to support themselves while completing their studies. Thus, even in countries without tuition fees, there is still a substantial amount of cost-sharing, because no higher education system covers students' educational and living costs completely.

\section{Method of the Study}

\subsection{Hypotheses}

According to the method chosen, the first step was to set out a framework within which to investigate the programme theory associated with cost-sharing. For this, four "hypotheses" were developed. The hypotheses pick up on key aspects of sustainability, effectiveness and equity of tuition fee policies in higher education.

- Hypothesis A: As private funding increases, total revenue of HEIs increases, if public funding (at least) remains constant.

- Hypothesis B: As the incentives to earn private funding increase, HEIs become more responsive to student demand, if they have an increased motivation to maximize revenue.

- Hypothesis C: Increasing private funding has a negative effect on student demand, if some students have liquidity or rate of return issues.

- Hypothesis D: Increasing private funding affects student choice of how and what to study, if some students have liquidity or rate of return issues.

All hypotheses start out from a very general description of the intervention observed by stating that private funding increases. This is in accordance with the broad scope for the analysis set by the terms of reference. Later in the project and in the final analysis the specificity of the intervention was increased by focusing on increases (or decreases) in tuition fees.

The first hypothesis (A) is very simple assuming that an increase in private funding will lead to a total increase in the revenues of HEIs. It has - as with the following hypotheses - a special focus on the three central challenges for cost-sharing; in this case on sustainability. The mechanism required for this to work appears not to be a mechanism at all under the common understanding, since it does not speak of reasoning or norms which affect decisions of the target group, but instead it is an assumption about the intervention in connection with another intervention, i.e. the amount of public funding allocated. On another level, however, 
it does make an assumption that increases in private funding will only be acceptable to the system (i.e. to students and to HEIs) if they are combined with (at least) stable public funding. This gives this posit almost the status of a meta-hypothesis, which provides the context for the following three hypotheses.

The second hypothesis (B) focuses on one of the expected behavioural changes - the change to the way HEIs act. It contains the expectation that more private funding will make HEIs act more like commercial enterprises, and focus more on the wishes of students as one of their major stakeholders (or customers). It contains a clear description of the mechanism which is expected to make this happen, i.e. HEIs will have an increased motivation to maximise revenue. In this, it makes an assumption about a change of culture and values, which will accompany the increase in private revenue.

The third and fourth hypotheses focus on expected changes to student behaviour. The third hypothesis (C) focuses directly on a much expressed expectation that increasing private funding will have a selective effect on students, and that some prospective students will decide against studying under the new conditions. The mechanism is that students will make their decision based on the money available to them now (i.e. their liquidity) and/or on considerations of the future financial value (i.e. rate of return) of participating in higher education, and that some will therefore decide against studying under these conditions.

The fourth and final hypothesis (D) is an attempt to be more nuanced about the possible outcome of decisions on liquidity and rates of return, since it posits that students do have some strategies available to them in order to decrease the financial impact of increases in private costs. This hypothesis expects that the outcome of decision-making may be that students change the way they study or what they study under the new conditions. For instance, studying part-time and working part-time or taking a subject area, where the costs of studying are lower (e.g. social science or business studies) or the financial benefits of the qualification are higher (e.g. engineering or law).

\subsection{Case Studies and Comparative Analysis}

The study investigates nine case studies of higher education reform in the period 1995-2010, in order to investigate the hypotheses described above-seven countries from inside the European Union and two from outside Europe. This selection of countries provides a variety of settings in which to investigate the effects. Different countries were chosen according to the following criteria: geographic coverage, economic strength, population size, enrolment numbers, share of students in private higher education, degree of public funding of institutions, changes to private funding, tuition fee policy, and student financial aid provision. The higher education systems covered are: Austria, Canada, England, Finland, Germany, Hungary, Poland, Portugal and South Korea. 
The case studies were written in a standardised manner, based on a strict template for structure and for the data and information sources to be used for each topic. They were written by the authors, but the data and information were provided by national experts, who also carried out interviews in their countries (again based on a standardised template) in order to further investigate certain topic areas, especially those for which little national data were systematically available.

Although the case study reports cover the whole breadth of cost-sharing (Orr et al. 2014b), for the comparative analysis the authors focused on changes to tuition fee policy, since they took the view that the investigation should focus on a clear policy intervention in order to facilitate comparison across the countries. It was surmised that the countries with the biggest and most rapid shifts in tuition fee policy would be most interesting for the study, since such shifts could be expected to have greater impact on student and HEI behaviour than a generally stable tuition fee policy. For this reason the cases were split into 'discontinuity countries' (Austria, England, Germany and Portugal) and 'continuity countries' (Canada, Finland, Hungary, Poland and South Korea) for the analysis. The table in Fig. 1 presents a summary overview of the country patterns.

\begin{tabular}{|l|l|l|l|}
\hline $\begin{array}{l}\text { Share of fee-paying students } \\
\text { (rows) }\end{array}$ & & & \\
\hline Increased & & $\begin{array}{l}\text { England 1998 } \\
\text { England 2006 } \\
\text { Germany 2006/07 } \\
\text { Austria 2001 }\end{array}$ \\
\hline Stayed the same & Finland & $\begin{array}{l}\text { Portugal 2003 } \\
\text { England 2012)* } \\
\text { South Korea } \\
\text { Canada }\end{array}$ \\
\hline Decreased & $\begin{array}{l}\text { Poland } \\
\text { Austria 2009 } \\
\text { Germany 2011-2013 }\end{array}$ & Stayed the same \\
\hline $\begin{array}{l}\text { Average amount paid per } \\
\text { student (columns) }\end{array}$ & Decreased & Increased \\
\hline
\end{tabular}

Fig. 1 Overview of tuition fee policy change in the period of investigation. Note When no year is given it means that any change was gradual. (England 2012)*: The 2012 tuition fee reform in England is outside the period of investigation of this study, but will be included where data are available and relevant for the purpose of this study. Source Orr et al. (2014a, p. 9) 


\section{Discontinuity Countries with Big Shifts in Fee Policy}

In the cases of England (1998 and 2006), Austria from 2001 and Germany (from 2006), both the share of students paying fees and the average fees increased. In Austria and Germany this was because fees were introduced. In the case of England (1998), fees were introduced, but there were waivers for certain student groups; from 2006 almost all students were paying fees and the fees had also risen to higher levels. The share of students paying fees stayed the same in the newest 2012 reform in England, but the fee levels rose again. In the case of Portugal, fees were introduced in 2003 and rose insubstantially until 2010. That makes England, in the most recent period, and Portugal in some ways similar to the continuity countries.

In the cases of Austria (2009) and Germany (following 2011), both the share of students paying fees and the average amount of fees decreased. In the cases of Austria and Germany, this was because the fees that had been introduced earlier in the 2000s were abolished (for all, but a small group of students).

\section{Continuity with Some Shifts in Fee Policy}

South Korea and Canada are examples of countries in which fees are a common part of the funding constellation for higher education. In both countries fees rose over time, but there was no substantial change to the share of students paying these fees. Thus, although the countries have fees, they are viewed as continuity countries in the analysis.

In the case of Hungary and Poland, the share of students paying fees decreased over time, which was to some extent made possible by the declining number of students due to demographic change (Orr et al. 2014a, p. 35). In Poland this development even led to fees decreasing on average.

In the case of Finland, aside from an experiment with fees for some foreign students, neither the policy on the amount of students paying fees (none), nor the fee level (zero) changed over the time period observed in the study.

\section{Analysis and Results}

The four hypotheses were tested by analysing statistical and survey data from nine countries, and by conducting interviews with key national informants. The concept of discontinuity versus continuity policies was used to identify the most interesting differences, although some changes in other areas of funding policy also made the continuity countries illuminating. The results of the analysis are summarised below.

In general, public funds to institutions do not decrease as private funds increasenot even on a per-student basis. 
An analysis of the data for the case-study countries shows that over the 15 year period of investigation, the general trend has been that public funding per student has increased, although this was not a constant upwards climb in most cases. Cases in which public income decreased significantly over longer stretches of time are Canada in the late 1990s, South Korea 1999-2001, England post-2007, or Austria 2004-2009. Further research suggests that these decreases in public per-student income have one of two main causes: either a serious economic downturn - this was the case in Canada in the early 1990s (with effects on public spending being delayed into the late 1990s), and in South Korea after the currency crisis of 1997/1998; or a fast enrolment growth, as in Poland in the 1990s to mid-2000s, and, albeit less pronounced, in Austria in the 2000s. In England, both factors appear to have worked together after 2007. Figure 2 shows the development of per-student income from fees and the public purse, which increased in parallel until 2007, when a system change becomes evident. In this case, therefore, England can be seen to be the only country in the set of case-study countries where HEI income is now largely increasing due to student fees. At the same time, this analysis hides the fact that the fees in England are offered to students as deferred payments, which they only begin to pay once they start earning a substantial wage. Until this point, the fees are indirectly funded through the public purse.

The conclusion, suggested by observations of the cases, is that the main principle of higher education funding remains "public first", with only England seemingly attempting to move to the principle of "private first". This conclusion is fortified by the fact that Poland and Hungary, and rather surprisingly South Korea, have used a decline in the number of students in order to increase their public funding per student.

What the data do not include are the more recent effects of the financial crisis from 2008 to 2009, which has taken some time to impact on public spending in certain countries. A case in point is Portugal, where recent figures suggest that

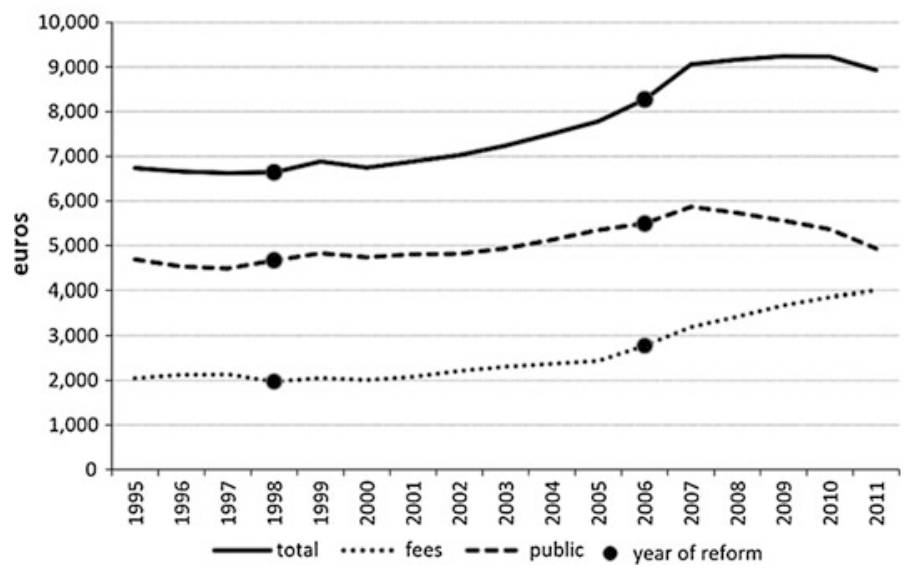

Fig. 2 Per-student income by source in English HEIs (1995-2011, constant prices). Source Orr et al. (2014a, p. 48) 
public spending per student has been declining (Cerdeira et al. 2014). As with other cases visible in the observation of the 15 year period of investigation, however, this may not be leading to a system change, but instead a temporary situation in the context of the public funding crisis. Only time can tell.

In general, responsiveness as a result of cost-sharing is less marked in traditional universities and more clearly visible in new institutions.

This was not a simple area to investigate and the conclusions here are based on interviews and proxy measures for responsiveness. The term 'responsiveness' used in Hypothesis B subsumes any kind of behaviour that can be understood as a (re) action to satisfy actual or anticipated user demand or to actively produce such demand. Several aspects of such behaviour were investigated in this study: the mix of disciplines institutions offer, diversity of provision, diversity in the modes of study, the focus on certain, financially attractive user groups, outreach activities and efforts to increase quality and relevance of instruction.

It turns out that the expectation that HEIs will become more responsive is based on a naïve business-based concept of the university. The study finds little evidence for HEIs "chasing the money" for a number of reasons. Firstly, in many cases, the incentive for an HEI to do this is low. This is because fees often only cover a fraction of the total costs of a study place, with the rest coming from the public purse, which has increasingly been using performance-based indicators and target agreements to steer HEIs from a distance (Orr and Jaeger 2009). Secondly, and in connection with new governance constellations in higher education, the autonomy of HEIs is often restricted, so that quick reactions to new demands in the market are limited (Eastermann et al. 2011). Thirdly, there are other incentives, particularly concerning research activities, which may be stronger and may therefore gain more attention on the part of the universities (OECD 2014; Wespel et al. 2013). Finally, universities are perhaps better understood as organisations framed by a college culture, in which prestige and excellence in certain disciplinary fields is valued more than reactions to external stimuli (Bergquist 1992).

What the study did find, in contrast, was that a number of case-study countries had been introducing new forms of HEI in order to have a more responsive higher education sector. A wave of newly established private institutions (e.g. in South Korea and Poland) and/or of an alternative type of public or private institution with an inherent vocational orientation was the result (e.g. $80 \%$ of student growth in Finland and $66 \%$ of growth in Austria was in the polytechnic/Fachhochschule sectors).- To some extent, such developments also take the pressure for change off the existing university sector, including change towards more responsiveness.

Demand for higher education has been increasing everywhere throughout the last two decades to such a degree that adverse effects of increased cost-sharing on participation are difficult to establish.

Both Hypotheses $\mathrm{C}$ and D expect that a change to the cost of studying would work as a mechanism to change students' behaviour regarding their enrolment and their modus of studying. In the case of Hypothesis $\mathrm{C}$, a downturn in the number of 


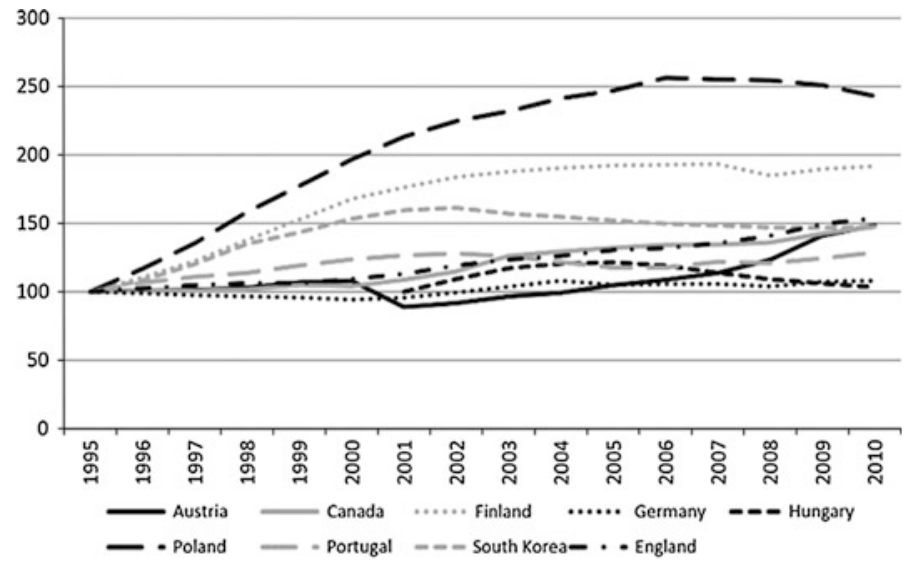

Fig. 3 Total enrollments in higher education $(1995=100)$. Source Orr et al. $(2014 a$, p. 79$)$

people enrolling for studies was expected. In the period investigated in this study, enrolment grew in all case study countries through to the mid-2000s, with declines or slowing of growth toward the end of 2000s - see Fig. 3. The case of Austria showed a dip in student numbers at the time of the introduction of the fees, but-as explained in the study - this is mostly related to the fees changing the incentive for non-students to enrol as student for such non-study benefits as cheaper medical insurance, cheaper urban travel etc. National studies showed only a small decline on the part of active-students related to the introduction of fees (Pechar and Wroblewski 2002) and Fig. 3 shows recovery and further growth in the number of students over time.

This pattern and further analyses in the study lead to four possible conclusions related to the effects of fees. The first is that the expected mechanism, that changes to students' liquidity or their evaluation of the returns on investment of studying would lead to a change in their enrolment behaviour, may occur, but not specifically because of fees alone. Fees are only a small part of student costs, in many cases, and looking at changes in the total cost structure for students over time provides a much more stable picture than one would expect if only looking at fees-see Fig. 4. Whilst the impact of the fees is clearly visible for England, it is non-apparent for Germany or Austria, where, inter alia, the drop in costs of clothing has had the largest impact on students' annual costs. Conversely, the rise in student costs for Finland, which does not raise fees, becomes visible.

The second possible explanation is also about putting tuition fees costs into a greater financial context. In many cases, study aid is provided to all students or targeted student groups in order to compensate for the fee costs. This led to the European Commission to define the major recommendation of the study as coupling study costs and study aid in a sensible manner (European Commission 2014). The study looked at the "out-of-pocket fees" of students by combining average fees and average support in the form of non-repayable and repayable study aid (grants 


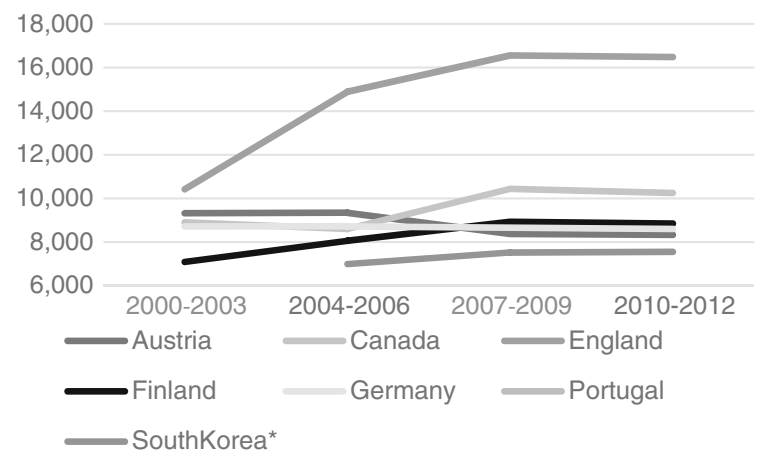

Fig. 4 Total annual costs to students in Euros including fees (constant prices 2011) Note In many cases the data are from national surveys, which are not carried out in the same year in every country. For this reason, the years have been banded. No multi-year data for Poland or Hungary. Source Orr et al. (2014a, p. 76)

and loans, respectively). The analysis showed that the "out-of-pocket fees" tend to remain under zero, which is not surprising under the assumption that such study aid is also meant to cover some part of students living costs. Only in South Korea do the costs remain above zero at around two thousand Euros per annum (constant prices). This stability is, in fact, the result of a policy whereby the annual increase in

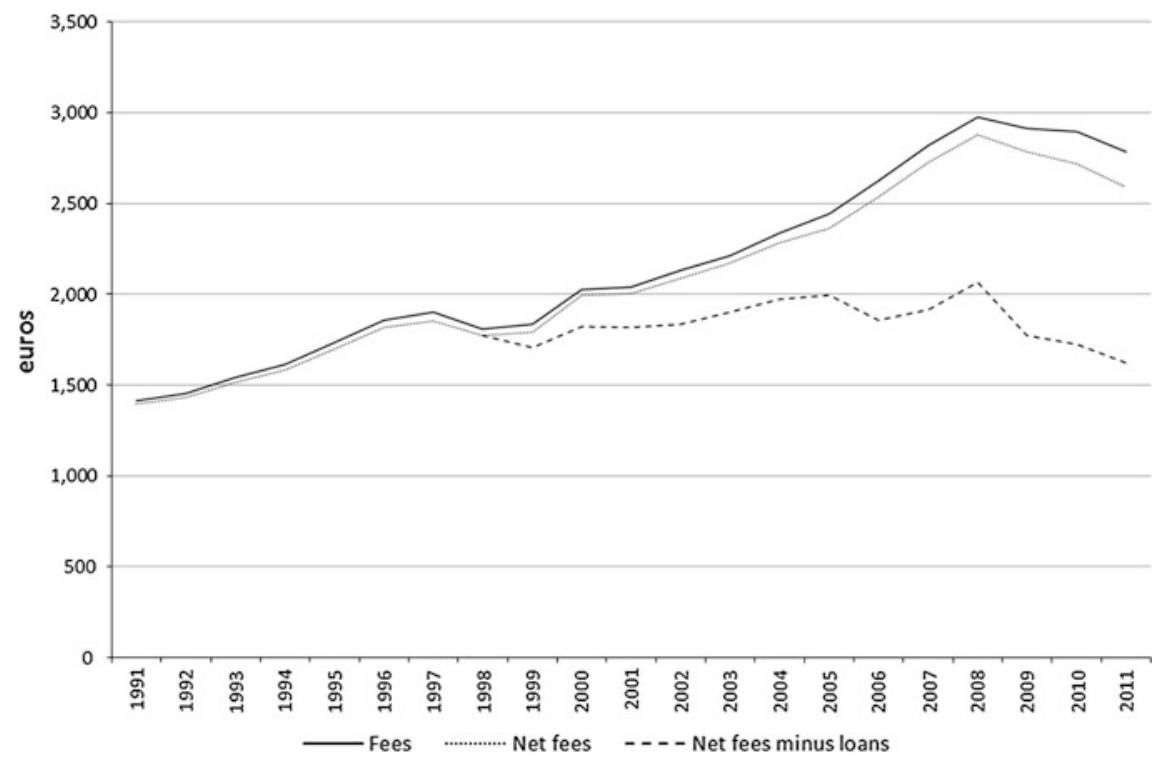

Fig. 5 Tuition fees and out-of-pocket fees in South Korean higher education (in won, constant prices 2011). Note Net fees $=$ fees minus grants, out-of-pocket fees $=$ net fees minus loans. Source Orr et al. (2014b, p. 424) 
fees is being compensated for through increasingly providing grants to students. This is the case in both private and public sectors-see Fig. 5 for a view of the public higher education sector.

The third possible explanation is that the mechanism of a change in financial costs is not strong enough to really have an impact. This could especially be the case in countries such as England, where there is a blanket cost of attending university or college and very little differentiation in the fee structure at Bachelor level (the focus of this study). This means that prospective students are presented with the binary choice of studying and paying the high fees (albeit deferred until they earn a regular wage on the labour market) or not studying at all. Indeed, two developments in the English context are particularly interesting. Firstly, that few student groups appear to have changed their enrolment patterns after the introduction of higher fees in 2012 (but all three previous explanations are also important in order to understand the English case) (UCAS 2012). Secondly, that HEIs have changed their support structures for new students over time. Whilst these largely provided certain groups of students (including students from underrepresented groups) with direct grants to offset the costs of their fees in the beginning, they are now using around $12 \%$ of funding income through fees to fund specific (non-financial) support initiatives for these groups (OFFA 2013). This is also in accordance with a recent national study in the United Kingdom looking at effective means to support widening participation, which sees costs as only one of the issues (Higher Education Academy 2012).

The fourth possible explanation is that there are effects, but that these only impact on small groups of students - and big effects on small groups look like small effects, even if you can see them. In the review of studies looking at students' socio-economic characteristics, no common patterns were really evident. However, it was also not possible to conclude that fee policy has a direct impact on the participation on underrepresented groups. In fact, in a number of countries (including Poland and England, which had clear data to show this) participation of underrepresented groups has been increasing. However, it should not be forgotten that these changes are happening within a higher education system which has been both expanding and diversifying. We know, for instance, that the non-university and the private sectors are more inclusive than the university sector, so if these sectors are growing, it means that higher education is offering more places, which are attractive or "acceptable" for new student populations. More subtle research, which was outside the remit of this study, is necessary to unpack such (new) effects of both vertical and horizontal differentiation by social background within the higher education system.

\section{Endnote}

In a possible continuum between empirical research and policy advice, the study presented here tends towards the latter. This has made it a very useful vehicle for stimulating new debates on cost-sharing and tuition fee policy in Europe and abroad 
(e.g. in Australia during the current reforms there). One of the central recommendations of the study was that policy-makers and disputants consider both the questions of sustainable funding of higher education provision, and equitable access and success for students together, since it can be observed that this is seldom the case. In Germany, which abolished all tuition fees in all Länder by 2014, the study was featured in a big article in Spiegel Online, but was not commented upon further. However, recently, the German Rectors' Conference has referred both to this study and a special German report on the development of public spending on teaching in higher education per student (Dohmen and Krempkow 2014) to call for a renewed discussion on tuition fees and their possible place in higher education funding. It is this type of triangulation of the results and re-connecting the findings to national contexts that should be the ultimate goal of comparative research. In this way, it can feed into national policy debates and decision-making processes. It is also hoped that the study will stimulate new research, which goes beyond a frequently encountered strong fixation on tuition fees as an isolated cost and an independent variable to view higher education funding in its larger real-life context.

Acknowledgments This paper draws heavily on the work executed jointly by Orr et al. (2014a, b), and the author would like to thank his counterparts for their work on the full report.

Open Access This chapter is distributed under the terms of the Creative Commons Attribution Noncommercial License, which permits any noncommercial use, distribution, and reproduction in any medium, provided the original author(s) and source are credited.

\section{References}

Andrews, M. (2013). Explaining positive deviance in public sector reforms in development (working paper). Harvard: Center for International Development at Harvard University.

Bergquist, W. H. (1992). The four cultures of the academy: Insights and strategies for improving leadership in collegiate organizations (Jossey bass higher and adult education). Jossey-Bass Inc.

Cerdeira, L., Machado-Taylor, M. L., Cabrito, B., \& Patrocínio, T. (2014). The impact of cost-sharing on accessibility and equity in Portuguese higher education. Paper presented at the 2nd EUA Funding Forum, Bergamo. http://www.eua.be/Libraries/Funding_Forum/EUA_ Bergamo_Cerdeira_Machado_Final.sflb.ashx

Dohmen, D., \& Krempkow, R. (2014). Die Entwicklung der Hochschulfinanzierung-von 2000 bis 2025 (the development of higher education funding between 2000 and 2025). Germany: Konrad Adenauer Stiftung.

Eastermann, T., Nokkala, T., \& Steinel, M. (2011). University autonomy in Europe II: the scorecard. http://www.eua.be/Libraries/Publications/University_Autonomy_in_Europe_II_-_ The_Scorecard.sflb.ashx

EU. (2002). On the collection and use of expertise by the commission: Principles and guidelinesimproving the knowledge base for better policies. http://ec.europa.eu/governance/docs/comm expertise_en.pdf

EU. (2009). Council conclusions of 12 May 2009 on a strategic framework for European cooperation in education and training (ET 2020). Official Journal of the European Union, 119 (2), 2-10. 
EU. (2011). Supporting growth and jobs - an agenda for the modernisation of Europe's higher education systems. http://ec.europa.eu/education/library/policy/modernisation_en.pdf

European Commission. (2014). Student support crucial for offsetting impact of university tuition fees, says report. http://europa.eu/rapid/press-release_IP-14-709_en.htm

Eurydice. (2012). National student fee and support systems 2011/12. Education, Audiovisual and Culture Executive Agency.

Higher Education Academy. (2012). Literature syntheses of the widening access, student retention and success national programmes archive: Report summaries. https://www.heacademy.ac.uk/ sites/default/files/WASRS_literature_syntheses_summary.pdf

Megginson, W. L., \& Netter, J. M. (2001). From state to market: A survey of empirical studies on privatization. Journal of Economic Literature, 39(2), 321-389.

OECD. (2014). Promoting research excellence-new approaches to funding. Paris: OECD Publishing.

OFFA, H. (2013). Access agreement and widening participation strategic assessment 2011-12 and national scholarship programme (Vol. 13). Retrieved from http://www.offa.org.uk/wpcontent/uploads/2012/07/2012-05+2012-13-OFFA+HEFCE-Access-Agreement-outcomesweb.pdf

Orr, D., \& Jaeger, M. (2009). Governance in German higher education: Competition versus negotiation of performance. In J. Huisman (Ed.), International perspectives on the governance of higher education (pp. 33-51). London: Routledge.

Orr, D., Wespel, J., \& Usher, A. (2014a). Do changes in cost-sharing have an impact on the behaviour of students and higher education institutions? Evidence from nine case studies (Vol. 1).

Orr, D., Wespel, J., \& Usher, A. (2014b). Do changes in cost-sharing have an impact on the behaviour of students and higher education institutions? Evidence from nine case studies.

Pawson, R. (2006). Evidence-based policy: A realist perspective. California: Sage.

Pawson, R., \& Tilley, N. (1997). Realistic evaluations. California: Sage.

Pawson, R., \& Tilley, N. (2004). Realist evaluation (prepared for British Cabinet Office) 1-36. http://www.communitymatters.com.au/RE_chapter.pdf

Pechar, H., \& Wroblewski, A. (2002). Retrospektive Schätzung studienaktiver Universitäten der Wissenschaften für 1996/97-2000/01. Project report to the BMBWK. Retrieved from http:// www.equi.at/dateien/stb_monit_pechar.pdf

Phillips, D. (2006). Comparative education: Method. Research in Comparative and International Education, 4(1), 304-319.

Sayer, A. (1992). Method in social science: A realist approach. London: Routledge.

Solesbury, W. (2001). Evidence based policy: Whence it came and where it's going (Vol. 1, pp. 111). https://www.kcl.ac.uk/sspp/departments/politicaleconomy/research/cep/pubs/papers/ assets/wp1.pdf

UCAS. (2012). Final end of cycle figures for 2012. http://www.ucas.com/sites/default/files/ucasend-of-cycle-report-2012.pdf

Wespel, J., Orr, D., \& Jaeger, M. (2013). The implications of excellence in research and teaching. Center for International Higher Education, 72, 13-15.

Westhorp, G. (2014). Realist impact evaluation-an introduction. Methods Lab. odi. org/methodslab. 